\title{
Gonadal infiltration in children with leukaemia and lymphoma
}

\author{
H REID AND HB MARSDEN \\ From the University of Manchester, Department of Pathology and Royal Manchester Children's Hospital, \\ Manchester, UK
}

SUMMARY In a postmortem survey of children with leukaemia and lymphoma, the overall incidence of testicular infiltration was $65 \%$ and of ovarian infiltration $66 \%$. In acute lymphoblastic leukaemia, testicular infiltration was found in 25 of 39 cases and ovarian infiltration in 6 of 12 cases. The majority of boys with acute lymphoblastic leukaemia and testicular infiltration also had infiltration in other organs; furthermore, in most cases without testicular infiltration leukaemic infiltration was found in other organs. The findings of this survey support the view that testicular infiltration is indicative of widespread disease.

In children with leukaemia, extramedullary sites have been incriminated as causes of relapse. The recent literature has emphasised testicular infiltration, its relationship to relapse, and its treatment in acute lymphoblastic leukaemia (ALL). ${ }^{1-3}$ In this paper we present our findings from a postmortem survey of the incidence of gonadal infiltration in children with leukaemia and lymphoma.

\section{Material and methods}

From the necropsy files at the Royal Manchester Children's Hospital slides from children with leukaemia and lymphoma were examined. In the majority of cases only a slide of one gonad was available. The period covered was from 1953 to early 1978, and the age range was 9 months to 17 years in the 65 boys and 9 days to 9 years in the 31 girls in the survey. The diagnoses were based on the clinical histories, necropsy findings, and the Manchester Children's Tumour Registry notes.

The gonads were examined for degree of infiltration, graded from 0 (absent) to $4+$ (heavily infiltrated), the type of infiltrate, the site, and any abnormal appearances of the gonad. The recognition of infiltration depended upon the presence of what we considered to be abnormal cells; small collections of mature lymphocytes were not regarded as an infiltrate.

Received for publication 31 August 1979

\section{Results}

In the Manchester Children's Tumour Registry from 1954 to early 1978 there were 834 cases of leukaemia, 703 of whom have died ( 391 boys and 312 girls). In our series, 74 of the leukaemia cases (85) were in the registry, 46 boys and 28 girls. So our necropsy survey covers $10.5 \%$ of all the fatal leukaemia cases in the registry, $12 \%$ of the boys and $9 \%$ of the girls.

Nine of the 10 lymphoma cases were in the registry, and during the same period 125 cases of non-Hodgkin's lymphoma were in the registry; 60 of the 83 boys have died, so our survey encompasses $15 \%$ of all the fatal non-Hodgkin's lymphoma cases in the registry.

Of the 65 boys in our survey, 39 had acute lymphocytic leukaemia (ALL) and, of these, 25 $(62 \%)$ had testicular infiltration (Table). Eight had acute myeloid leukaemia (AML) and, of these, five had testicular infiltration (Fig. 1). In most of the cases of ALL, the infiltration in the testis was diffuse (Figs 2-5), in 11 cases it was heavy (graded 3+ and $4+)$, and in 16 there was perivascular infiltration of the tunica. In five of the 11 cases where there was heavy infiltration of the testes leukaemic cells were seen in the testicular tubules. In one of the cases of leukaemic conversion of lymphoma there was destruction of tubules by leukaemic cells similar to that described by Kuo et al. ${ }^{2}$ (Fig. 6). In the lymphoma 
Incidence of gonadal infiltration in cases of leukaemia and lymphoma

\begin{tabular}{|c|c|c|c|c|c|c|}
\hline \multirow[t]{2}{*}{ Diagnosis } & \multicolumn{3}{|c|}{ Testis } & \multicolumn{3}{|c|}{ Ovary } \\
\hline & No. & No. infiltrated & $\%$ & No. & No. infiltrated & $\%$ \\
\hline $\begin{array}{l}\text { ALL } \\
\text { AML } \\
\text { AMML } \\
\text { Lymphoma } \\
\text { LYM } \rightarrow \text { L } \\
\text { Others }\end{array}$ & $\begin{array}{r}39 \\
8 \\
2 \\
10 \\
1 \\
5\end{array}$ & $\begin{array}{r}25 \\
5 \\
2 \\
5 \\
1 \\
4\end{array}$ & $\begin{array}{r}62 \\
62 \\
100 \\
50 \\
100 \\
80\end{array}$ & $\begin{array}{r}12 \\
9 \\
3 \\
0 \\
3 \\
4\end{array}$ & $\begin{array}{l}6 \\
6 \\
3 \\
\\
2 \\
3\end{array}$ & $\begin{array}{r}50 \\
67 \\
100 \\
\\
67 \\
75\end{array}$ \\
\hline Total & 65 & 42 & 65 & 31 & 20 & 66 \\
\hline
\end{tabular}

AMML = acute myelomonocytic leukaemia $; \quad L Y M \rightarrow L=$ leukaemic conversion of lymphoma.

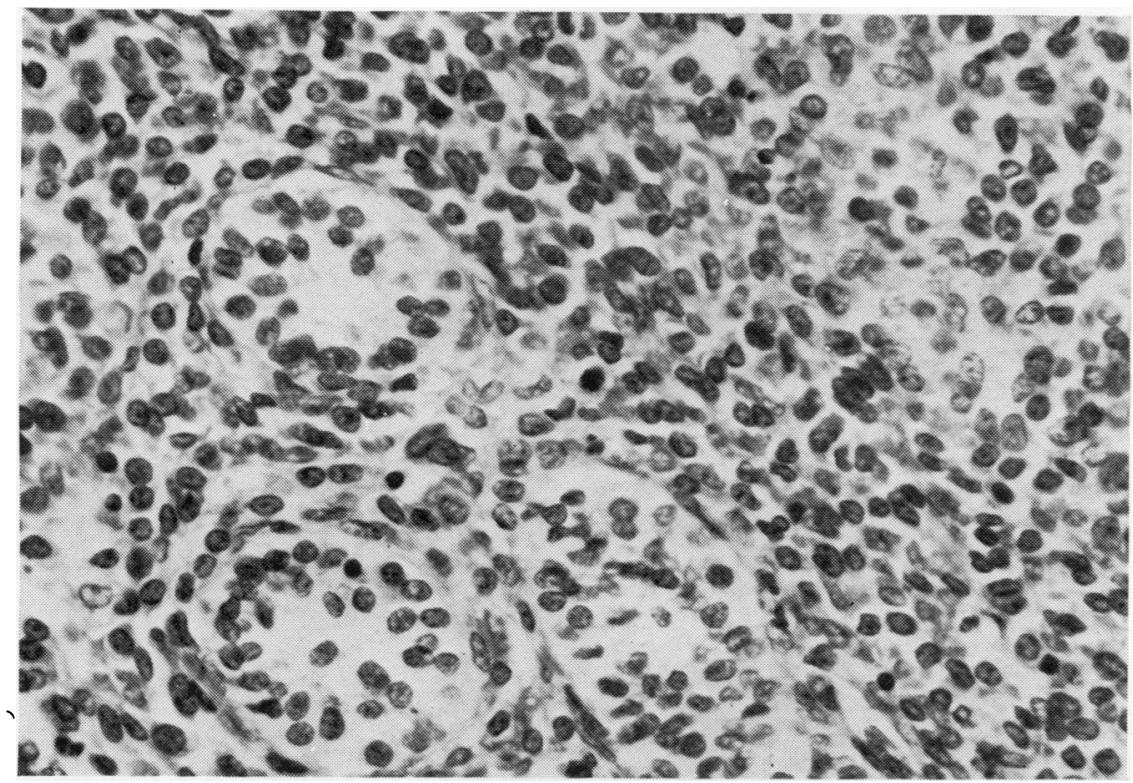

Fig. 1 Testis of a 9-year-old boy with acute myeloid leukaemia showing heavy interstitial leukaemic infiltration obscuring the tubules. (Haematoxylin and eosin $\times 500)$

cases, the testicular infiltration was diffuse and not focal.

Although the number of girls was smaller, six of the 12 with ALL had ovarian infiltration (Fig. 7). The overall infiltration rate was $66 \%$ (Table). The cases of acute myeloid and acute myelomonocytic leukaemia had a higher rate of infiltration than those of ALL, and in four of the nine ovaries in this group with leukaemic infiltration there was a large mass of leukaemic cells in the medulla (Fig. 8). The leukaemic infiltration was mainly in the medulla in the cases of ALL; it was mainly perivascular and mild $(1+$ and $2+)$. In two cases of leukaemic conversion of lymphoma the cortex was also infiltrated with reduction of oogonia (Fig. 9).

Other changes were seen in the gonads. In the ALL cases, of those with heavy to severe leukaemic infiltration (grades 3 and 4) of the testis (7 cases) four showed tubular loss; two with mild leukaemic infiltration had thickening of the tubular basement membrane. Also in the ALL cases, seven of the 14 boys aged 9 and over had few spermatogonia in the tubules, three of the seven testes which did not show reduced spermatogonia were not infiltrated, and one showed destruction of tubules by the infiltrate.

In the AML and AMML cases, four of six boys aged 9 and over showed reduced spermatogonia; of the other cases, one had mild leukaemic infiltration and the other testis was not infiltrated.

In the lymphoma cases, four were aged 9 and over, of whom three showed reduced spermatogonia, including one with no testicular infiltrate. Three cases in this group showed marked interstitial fibrosis of the testis; one was a 7-year-old who had had testicular irradiation, and three showed tubular basement membrane thickening. One lymphoma cases without testicular infiltration showed tubular loss. Interstitial fibrosis was present in three cases 


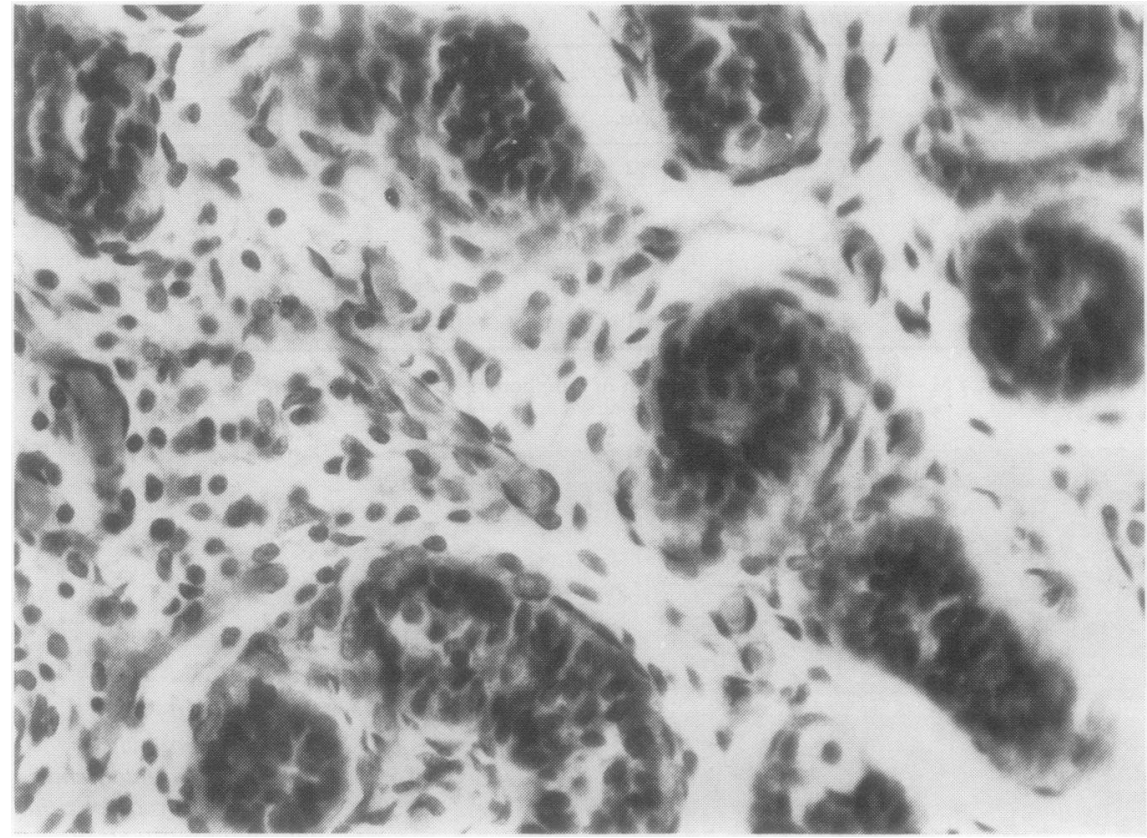

Fig. 2 Testis of a 2-year-old boy with ALL showing a mild focal interstitial leukaemic infiltration grade 1. ( $H$ and $E$ $\times 500$ )

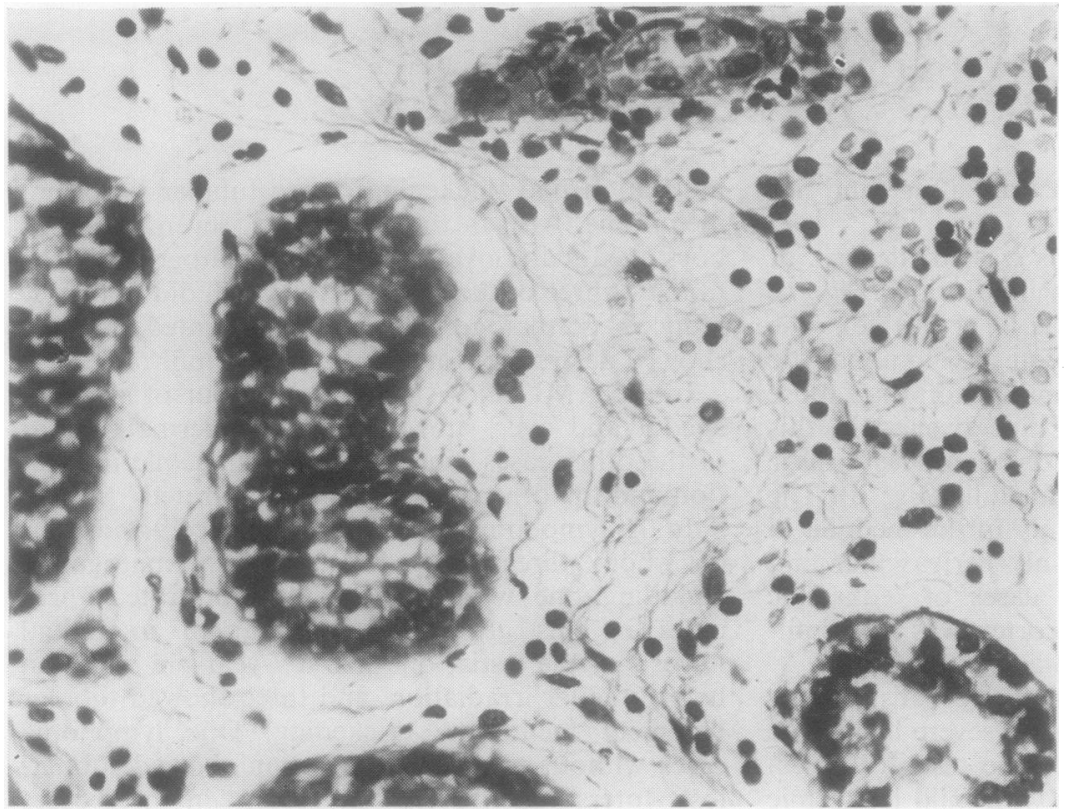

Fig. 3 Testis of a 10-yearold boy with ALL showing grade 2 leukaemic infiltration which is diffuse. No apparent reduction of spermatogonia. ( $H$ and $E \times 500$ ) 


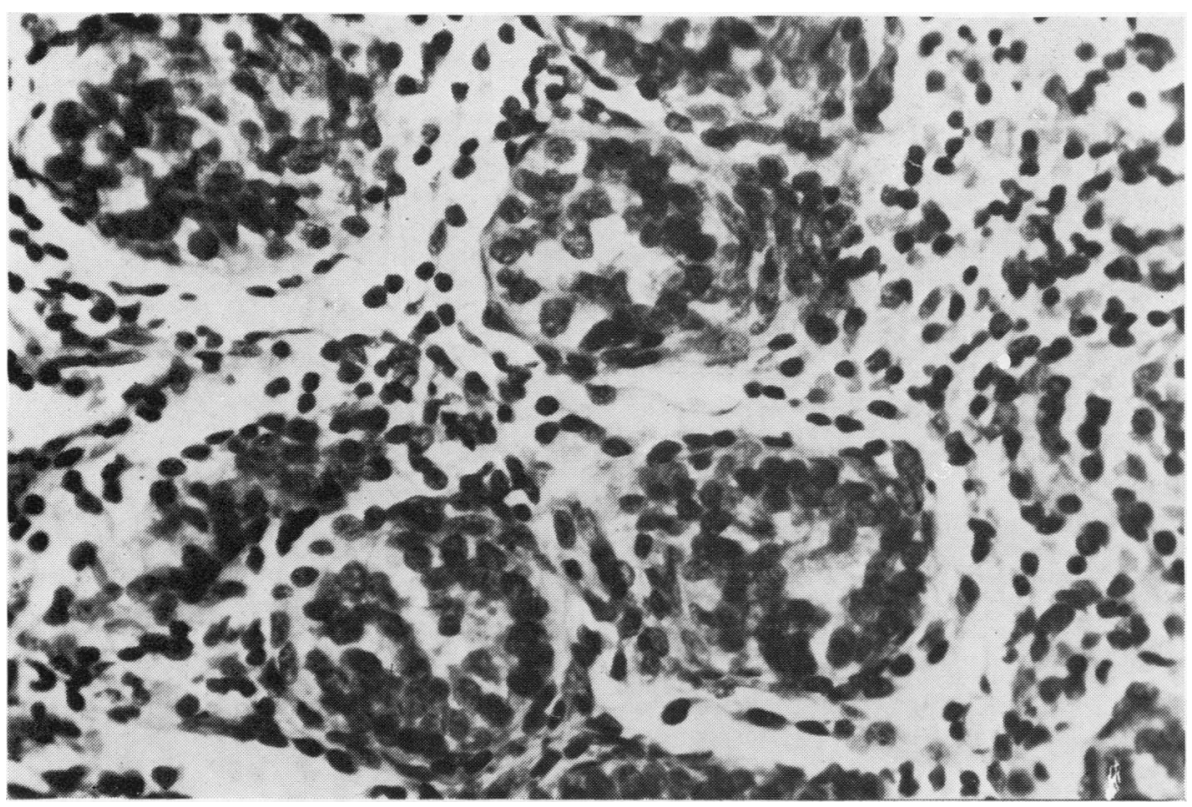

Fig. 4 Testis of $a$ 4-year-old boy with ALL showing grade 3 leukaemic

infiltration.

( $H$ and $E \times 500)$

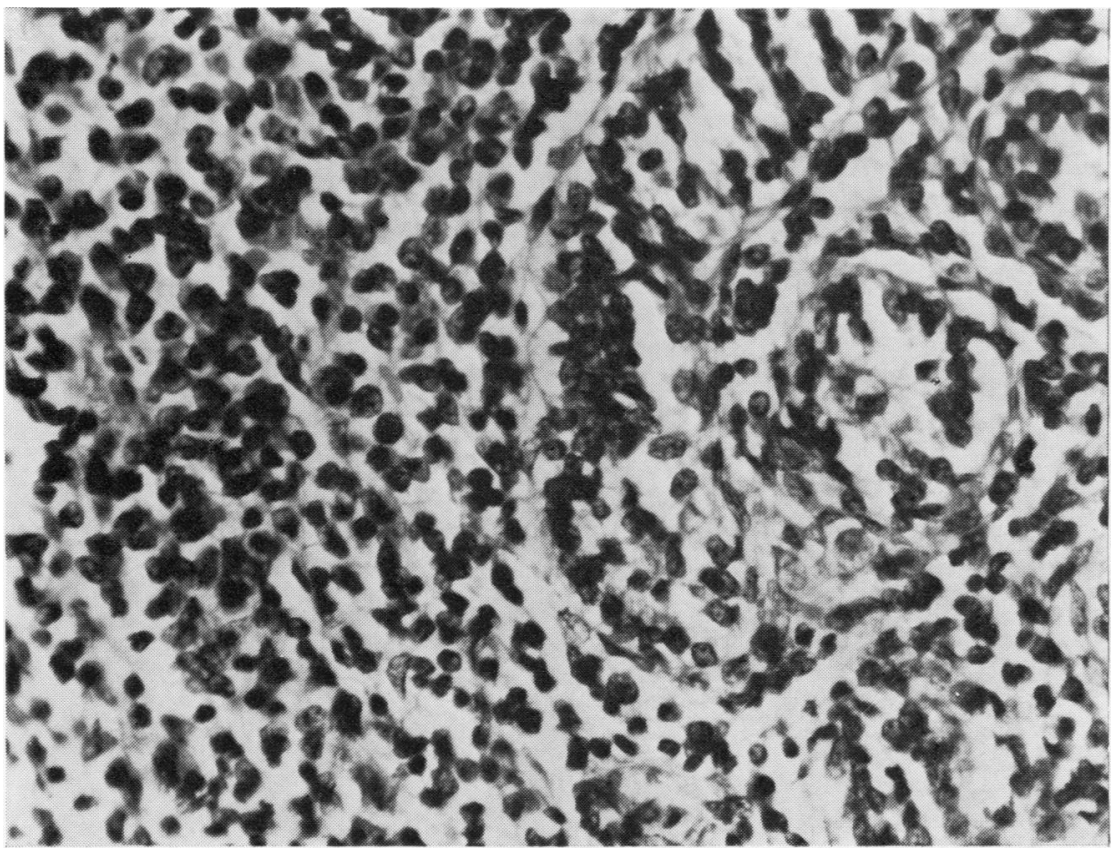

Fig. 5 Testis of a $5 \frac{1}{2}$-year-old boy with ALL showing grade 4 leukaemic infiltration. Tubules are obscured by the infiltrate. ( $H$ and $E$ $\times 500)$ 


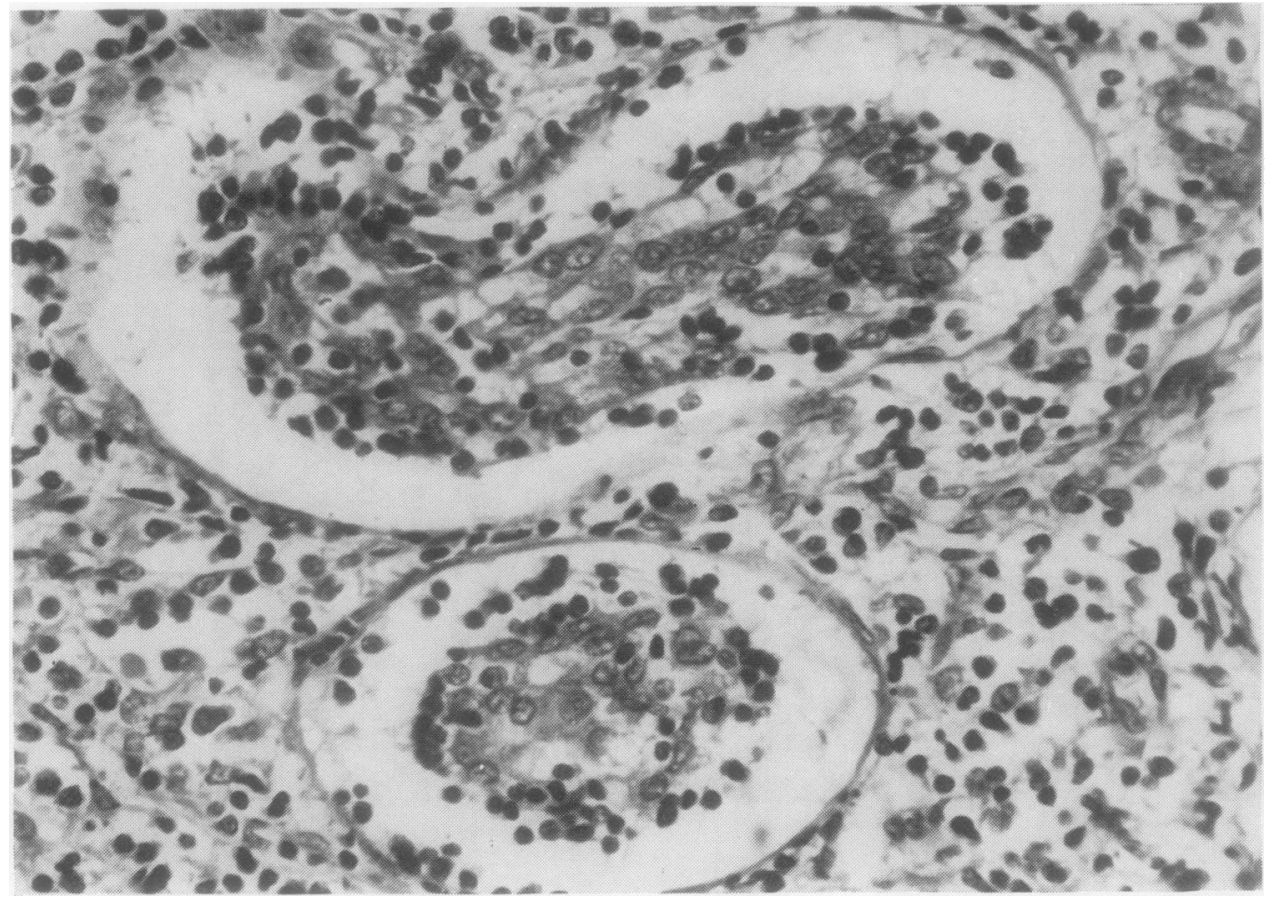

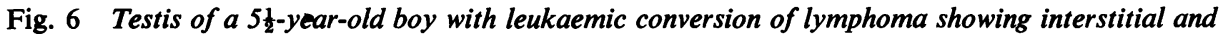
tubular infiltration. ( $H$ and $E \times 500)$

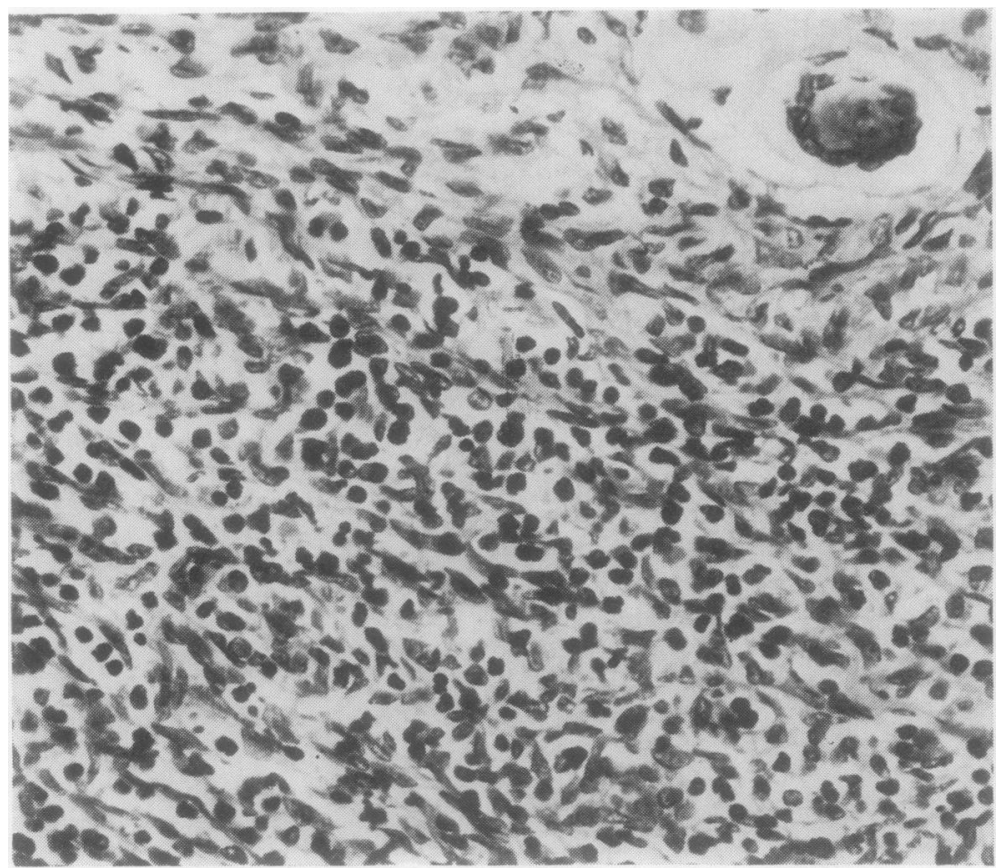

Fig. 7 Ovary of a 9-year-old girl with $A L L$ showing leukaemic infiltration of the medulla. $(H$ and $E \times 500)$ 

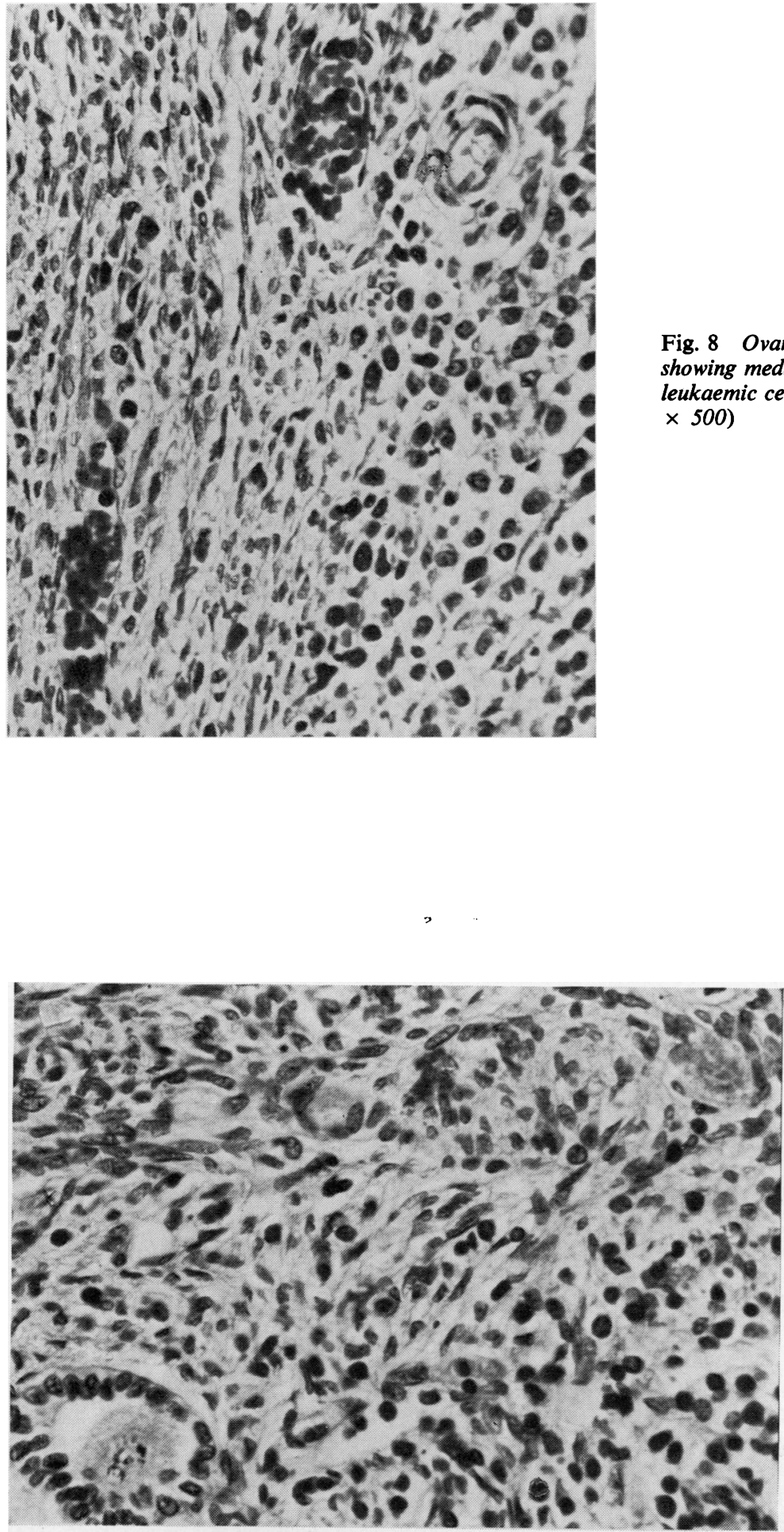

Fig. 8 Ovary of a 1-year-old girl with $A M L$ showing medullary leukaemic infiltration with leukaemic cells in two capillaries. ( $H$ and $E$ $\times 500)$
Fig. 9 Ovary of a 9-year-old girl with leukaemia showing mild leukaemic infiltration in the cortex: there was also mild leukaemic infiltration of the medulla in this case. ( $H$ and $E$ $\times 500)$ 
of ALL with leukaemic infiltration.

In the ovaries of ALL cases no loss of oogonia was seen apart from one ovary which was almost totally replaced by fibrous tissue, but, in two cases of leukaemic conversion of lymphoma, oogonia were reduced. In one of the AML cases there was loss of oogonia but no cortical fibrosis.

In all the cases of ALL, slides of bone marrow and other organs, including two or three of liver, spleen, and kidney, were examined. Only two cases had testicular infiltration, both of a mild degree, but no other evidence of leukaemic infiltration; one had died of measles pneumonia and the other of septicaemia. Three cases had no infiltration in the testis or other sites examined; of the 11 other cases with no testicular infiltration, seven had marked leukaemic infiltration in other organs.

\section{Discussion}

Four previous surveys have been published on gonadal infiltration in leukaemia. ${ }^{1-6}$ Givler $^{4}$ found that $64 \%$ of 140 males with acute leukaemia had testicular infiltration at necropsy. In his series no ages were given, but 70 cases had ALL, and 48 of these showed testicular infiltration, that is, $69 \%$. Finklestein et al. ${ }^{1}$ quoted a personal communication that $22(97 \%)$ of 24 boys had leukaemic infiltration of the testis in consecutive cases of generalised leukaemia, and this was, therefore, a more selected group than ours. Sullivan and Hrgovic ${ }^{5}$ found that $28 \%$ had testicular infiltration in their series of leukaemic children at necropsy; a higher percentage, $45 \%$, was found in those with AMML and acute monocytic leukaemia. Haggar et al. ${ }^{6}$ quoted a personal communication that $48 \%$ of males in a survey of acute leukaemia (340 cases) had testicular infiltration, though no breakdown as to age and type of leukaemia is given.

From these surveys our incidence of testicular infiltration is similar to that of Givler $^{4}$ and higher than that of Sullivan and Hrgovic. ${ }^{5}$ In Sullivan and Hrgovic's series, ${ }^{5}$ ovarian leukaemic infiltration was found in nine $(11.4 \%)$ of 78 cases; they also quoted another series where $29(36 \%)$ of 80 girls with acute leukaemia had ovarian infiltration. In the series that Haggar et al. ${ }^{6}$ quoted, $24 \%$ had ovarian infiltration in acute leukaemia. In our series, six out of 12 girls with ALL had ovarian infiltration, and of all those with leukaemia (31 cases), 20 had leukaemic infiltration in the ovary. This is important as the prognosis had been shown to be worse in boys with ALL than in girls, ${ }^{7}$ and it has been suggested that the testis as a sanctuary organ may be responsible for some of this difference. ${ }^{7}$ If the rate of ovarian infiltration is similar to that of testicular infiltration in ALL, as we would like to suggest, factors other than testicular infiltration may be more important in this difference between boys and girls.

The finding of widespread leukaemic infiltration in those cases with mild testicular infiltration and also the fact that the majority of those without gonadal infiltration had leukaemic infiltration support the view that testicular infiltration is not the only reservoir of leukaemic cells causing bone marrow relapse but that it is indicative of widespread disease. It is also significant that the majority of those without testicular infiltration had leukaemic involvement of other organs, and in seven of these cases the organs were heavily infiltrated, although we recognise that this may be a sampling error as only one gonad was examined.

Givler ${ }^{4}$ also emphasised the multiple sites of leukaemic infiltration in his cases and suggested that there were many microscopic leukaemic deposits in treated patients. Studies in children in apparently complete remission from their leukaemia during life and post mortem have been done, ${ }^{8}$ and $45 \%$ of cases have been found to have leukaemic deposits, further evidence in favour of this view. In a study of children after bone marrow relapse, ${ }^{9}$ prognosis was found to be poor, and the authors concluded that children with ALL have a single chance of cure at the time of diagnosis. This could be because of widespread leukaemic infiltrates occurring in these children. The effects of therapy on the gonads are difficult to assess in this retrospective study though the impression was gained that spermatogonia were reduced in older boys; half of those with ALL showed reduction of spermatogonia; five of these seven cases had been treated with cyclophosphamide and/or cytosine arabinoside, drugs which are associated with a reduced tubular fertility index. ${ }^{10}$ In the case of lymphoma, where testicular irradiation had been given there was marked interstitial fibrosis.

Since widespread leukaemic infiltrates have been found at necropsy and in studies on children in apparent remission, other extramedullary sites, apart from the meninges and testes, could well present further problems for therapy.

Our thanks are due to Dr J Birch for the data from the Children's Tumour Registry.

\section{References}

1 Finklestein JZ, Dyment PG, Hammond GD. Leukemic infiltration of the testes during bone marrow remission. Pediatrics 1969;43:1042-5.

${ }^{2}$ Kuo T-T, Tschang T-P, Chu J-Y. Testicular relapse in childhood acute lymphocytic leukemia during bone marrow remission. Cancer 1976;38:2604-12.

${ }^{3}$ Stoffel TJ, Nesbit ME, Levitt SH. Extramedullary involvement of the testes in childhood leukemia. Cancer 1975; 
35:1203-11.

${ }^{4}$ Givler RL. Testicular involvement in leukemia and lymphoma. Cancer 1969;23:1290-5.

${ }^{5}$ Sullivan MP, Hrgovic M. Clinical Pediatric Oncology. Sutow WW, Vietti TJ, Fernbach DJ, eds. Mosby, 1977.

- Haggar RA, MacMillan AB, Thompson DG. Leukemic infiltration of testis. Can J Surg 1969;12:197-201.

${ }^{7}$ Baumer JH, Mott MG. Sex and prognosis in childhood acute lymphoblastic leukaemia. Lancet 1978;2:128-9.

${ }^{8}$ Leader. Testicular infiltrates in childhood leukaemia: harbour or harbinger? Lancet 1978;2:136-7.
- Cornbleet MA, Chessells JM. Bone marrow relapse in acute lymphoblastic leukaemia in childhood. $\mathrm{Br} \mathrm{Med} \mathrm{J}$ 1978;2:104-6.

${ }^{10}$ Lendon M, Hann IM, Palmer MK, Shalet SM, Morris Jones PH. Testicular histology after combination chemotherapy in childhood for acute lymphoblastic leukaemia. Lancet 1978;2:439-41.

Requests for reprints to: Dr $\mathbf{H}$ Reid, Department of Pathology, Stopford Building, The University, Manchester M13 9PT, UK.

\section{Reports and Bulletins prepared by the Association of Clinical Biochemists}

The following reports and bulletins are published by the Association of Clinical Biochemists. They may be obtained from The Publishing Department, British Medical Journal (ACB Technical Bulletins), BMA House, Tavistock Square, London WC1H 9JR. Overseas readers should remit by British Postal or Money Order.

SCIENTIFIC REVIEWS (price $£ 1 \cdot 00 / \$ 2.00$ each)

1 The assessment of thyroid function March 1971 FV FLYNN and JR HOBBS

2 Renal function tests suitable for clinical practice January 1972 FL MITCHELL, N VEALL, and RWE WATTS

3 Biochemical tests for the assessment of fetoplacental function May 1975 CE WILDE and RE OAKEY

4 Test of exocrine pancreatic function March 1977 AH GOWENLOCK

5 Assay of cholinesterase in clinical chemistry March 1979 ELSIE SILK, J KING, and MARY WHITTAKER

TECHNICAL BULLETINS (price $£ 1 \cdot 00 / \$ 2.00$ each)

22 Bilirubin standards and the determination of bilirubin by manual and technicon AutoAnalyzer methods January 1971 BARBARA BILLING, RUTH HASLAM, and N WALD

23 Interchangeable cells for spectrophotometers and fluorimeters September 1971 sS BROWN and AH GOWENLOCK

24 Simple tests to detect poisons March 1972 BW MEADE et al.

25 Blood gas analysers May 1972 K DIXON

26 Kits for enzyme activity determination September 1972 SB ROSALKI and D TARLOW

27 Assessment of pumps suitable for incorporation into existing continuous flow analytical systems November 1972 A FLECK et al.

28 Routine clinical measurements of transferrin in human serum September 1973 K DIXON
29 Control materials for clinical biochemistry (5th edition) September 1973 JF STEVENS

30 Notes on the quality of performance of serum cholesterol assays September 1973 sS BROWN

31 Determination of uric acid in blood and in urine July 1974 RWE WATTS

32 A survey of amino acid analysers readily available in the United Kingdom September 1974 JE CARLYLE and P PURKISS

33 Definitions of some words and terms used in automated analysis November 1974 A FLECK, R ROBINSON, SS BROWN, and JR HOBBS

34 Measurement of albumin in the sera of patients January 1975 LINDA SLATER, PM CARTER, and JR HOBBS

35 Investigation of the validity of temperature correction factors for serum aspartate and alanine transaminases March 1975 SB ROSALKI et al.

36 Factors influencing the assay of creatinine November 1975 JGH COOK

37 A survey of enzyme reaction rate analysers readily available in the United Kingdom July 1977 RA SAUNDERS and RF BURNS

38 Transport of specimens for clinical chemistry analysis November 1977 P WILDING, JF ZILVA, and CE WILDE

39 A scheme for the evaluation of diagnostic kits May 1978 PH LLOYD

40 A practical guide to gamma-counting in radioimmunoassay January 1980 CE WILDE and D OTTEWELL 